\title{
Features and trends of the Russian economy transformation process
}

\author{
Tatyana Zhukova ${ }^{1}$, Ilona Avlasenko ${ }^{1}$, and Lyudmila Avlasenko ${ }^{1}$ \\ ${ }^{1}$ Don State Technical University, Gagarin Square, 1, Rostov-on-Don, Rostov Region, 344002, Russia
}

\begin{abstract}
The article deals with the issues of the transformational process of the Russian economy in recent years. It is emphasized that the formation of modern economic space occurs against the background of constantly changing conditions of economic reality. Trends in the development of the Russian economy are considered, the peculiarities of the Russian national economy are analyzed, taking into account its basic characteristics and development prospects. Particularly relevant is the consideration of transformational processes in connection with the formation of new standards of economic interconnections and opportunities for modern production. The main tasks and problems of Russian economic development with changing international priorities and strategic world transformations are noted. The special role of digitalization of society in the formation of modern business models, the identification of the advantages of digital reality is emphasized in this article. It is also highlighted that the changing conditions for the formation of the economic space is associated with the birth of a number of problems, including the strengthening of the role of state regulation of the public economy of Russia, the search for new instruments for the legal regulation of the national economy. Adapting the Russian economy to a constantly changing competitive market, the search for competitive advantages will mean the possibility for the Russian national economy to become a full member of the world community.
\end{abstract}

\section{Introduction}

The economic dynamics of recent years have followed the path of transformation of the market relations. This factor determined the main trend in the development of the economy, aimed at restructuring the economy, economic growth and innovative development. For the progressive development of the Russian economy, the main programs were developed based on the integration of spheres and sectors of the national economy.

One of the legacies of the past for the Russian economy was the persistence of imbalances in its structure and the dependent nature of raw materials, based on the advantages of a country with sufficient resource potential. This led to a high material and energy intensity of the products produced. Imbalances in the structure of production were supplemented by uneven equipping of the market with products of consumer and

\footnotetext{
*Corresponding author: tzhukova.work@ya.ru
} 
production demand. These advantages were not competitive, which led to the production of products that did not meet the standards of modern society [1].

The problem of further development of economic potential has always been associated with the raw materials nature of social production and the role of the country as a raw material state. Further economic development has created new challenges as technological, economic and social progress has evolved. The formation of new business sectors was integrated with the new state of the market and aggregate demand.

The elimination of negative trends and phenomena was relevant during the formation of market relations in Russia. This problem formed an insufficient supply of aggregate demand for socially necessary goods and services that could not compete in quality with the products of the leading countries of the world. The focus on the heavy sector of the economy gave rise to problems related to the satisfaction of the market with the products of the second division.

The underdevelopment of high-tech industries has led to an increase in the share of imports in aggregate demand. Traditional industries that take advantage of the competitive advantages of developed traditional production, do not have priority development potential and do not receive financial bonuses have also suffered losses. Machine-building, machine tool building, instrument-making, etc., instead of the expected improvement in the quality of production and growth in profitability of production, on the contrary, systematically left the domestic market, giving way to imported products [2].

The weak adaptation of large production to transformational processes and the inability to adapt economic advantages in conditions of fierce competition did not allow the Russian large business to outstrip the steadily developed countries in saturating both the consumer market and the market for means of production with high-quality products. The most significant damage occurred in industries aimed at satisfying the population with consumer goods [3].

\section{Materials and methods}

The object of the study is the Russian economy, which is in a state of transformation under the influence of modern processes of forming a single world economic space.

The subject of the study is modern transformational processes taking place in the modern economy of Russia. The gradual transformation of market relations in the country's economy is the basis for the analysis of the problems of forming clusters of the economic space of modern Russia.

The possession of competitive advantages, mistakes and trends in the formation of a market economy in Russia certainly imprint its further transformation and form the path of movement towards a new economic reality in the system of world economic relations.

The study of the processes of transformation of the Russian economy in the context of increased competition contributes to the definition of an economic development strategy. Qualitative analysis of economic processes is aimed at determining the factors affecting the ability of the Russian economy to improve itself, to identify the main impulse motives for its self-development as a system. The analysis of statistical material helps to identify the main trends in the development of the Russian economy at each stage of the transformation of the economy.

Quantitative research involves the use of a digital base to identify the vector development of the economy, reflecting the dynamics of economic relationships. The use of economic statistics reveals processes of stabilization or stagnation of the economic sector, indicating instability in this area. Statistical analysis reveals the scope of tension or economic growth. 
Qualitative analysis reflects the factor impact on the business environment, the sequence of economic transformations in the process of forming the country's priorityoriented economy.

In this article theoretical and methodological approaches are used to studying the specifics of the national economy of Russia in the context of the transformation of market relations and the formation of new forms of business space. Possibilities and prospects of the Russian economy taking into account resource potential and its further improvement in transition to a new economic reality are considered. Analytical studies are used to clarify the reasons for the phenomenon being studied. Statistical analysis is the basis of evidence.

\section{Results}

A characteristic feature of business transformation today is compliance with new directions and trends in the development of the world economy. Entrepreneurship in the context of the transition to a digital economy should become the basis of a national economy that can quickly respond to changes in the forms and methods of business projects in order to meet the needs of modern society. Moreover, here the main task is to take into account all the factors of influence on the structure of the economy and its internal source of development. Taking into account the peculiarities of the country's economic potential will allow to form the easiest entry of the country's economy into the realities of modern production.

Russian business is gradually adapting to the new requirements of the economy and forms business processes based on strategic development priorities, among which we can note the further introduction of elements of innovation, the search for creative development of business models. The use of human potential is gradually taking on new forms, the creative nature of the thinking of workers, startups and other innovative forms of employment are becoming the basis of the economy. Of course, such projects require both financial and intellectual resources, shaped by the capabilities of each country's economy. Therefore, special attention should be paid to the innovative capabilities of each business entity [4].

The basis of the transformational process, of course, is new forms of doing business, allowing large corporations to ensure the superiority of a technical and innovative nature. New technologies are becoming an integral part of the formation of leadership positions of enterprises mastering new business projects and organizational innovative forms.

Technological leadership is based on information technologies, which have become the basis of modern production and accompany business processes until profit.

In the context of the transition to a digital economy, the combination of information technologies and elements of socio-ethical marketing, as well as technologies of the "lean" nature of the production process, becomes a priority.

Today, the basic blocks of transformation of Russian business have been formed, associated with advanced trends in technical and economic development, among which, first of all, the transition to digital technologies should be called. Such blocks include the following:

- Transition to a new creative format of doing business;

- The operation of enterprises is based on information and communication technologies;

- Further integration of the spheres of national economy and, as a result, high economic results associated with the growth of the profitable sector of the economy;

- Active use of human potential, increased entrepreneurial activity, start-ups and the search for other ways to increase productivity [5].

In an effort to make full use of the acquisitions of the new reality, the economy is inevitably confronted with the problems created by that reality itself. Always one of the obstacles is the lag behind the regulatory framework from objectively formed economic 
relations. Therefore, in order to implement the newly emerging forms of doing business, it is necessary to lay the foundation that allows all market entities to realize their economic interests.

Another obstacle to the transformative development of market relations is the opportunity not only to use certain advantages, but also to develop technological potential, which will enable the Russian economy to integrate into the world economic space systematically. The coming period of restoring economic ties and the process of import substitution made it possible to transition to a new equilibrium state of the economy, which took a significant amount of time.

Over the past three decades, the Russian economy has been dominated by the problem of preventing a crisis in the economy, as well as ensuring accelerated economic growth and improving wealth. The Russian economy, which operates on market principles of economy, has formed a trend of accelerated development and entry into the system of world economic ties.

It is known that the dependence of the Russian economy on the conditions of world markets in connection with the entry into the structure of world economic ties, determined its economic status as a raw material economy of the world economy. On the one hand, this led to an increase in wealth, and on the other, it formed the economic status of the Russian economy as a raw material country. The result was a significant dependence on world market conditions, which is associated with the dynamics of foreign economies [6].

Due to Russia's unique ability to possess significant natural resources, energy, raw materials and other resource opportunities in the future will constitute a significant share in the structure of the product, including for export. This trend is now long-term.

Restoration of production of leading basic products, measures of protection against unfair competition, will contribute to the preservation of domestic traditions of production of high-quality products, as well as to solving problems of overcoming significant differences in the levels of economic development of the regions. The development of significant industries of the national economy will allow combining the development of high technologies and preventing the formation of social problems [7].

The production of high-tech goods and services contributes to solving a number of problems, including those related to the growth of the well-being of the country's population, the formation of environmentally sound production, and the formation of socioethical marketing. The products of the new economy are characterized by intense changes in quality and growth in gross domestic product (GDP).

Positive results, which are the logical completion of the refraction of economic relations, will become the basis for the formation of a new economic space in Russia.

In 2017, the Russian economy emerged from the recession of recent years, as a result of which the gross domestic product grew by almost $1.5 \%$. Although modest, this indicator is indicative of macroeconomic stability [8].

However, despite the market mechanisms formed in Russia, their effect was weakened by structural factors associated with the monopoly of the economy, as well as high risks that accompanied business development.

In2017-2018, relatively low indicators of economic freedom and competition are traced in Russia. In the ranking of competitiveness of world economic organizations, Russia was one of the eighth dozen countries, which reflects the weak position of the country's economic security.

Inherited from the previous model, the Russian economy retained the raw material nature of economic relations, an orientation towards the established nature of doing business, based on traditional production models.

Each of the sectors of the Russian economy has its own potential for further vector development related to the integration of spheres and industries and the formation of the 
main clusters of the public economy. Each sector has its own competitive advantage, which affects its profitability and economic efficiency. The commodity sector is characterized by high returns (about 20\%) with low internal efficiency. The large non-oil sector has a lower return (about 10\%). Small businesses have even lower returns $(5 \%)$.

Small and medium-sized businesses today are the basis for the development of many economies, compensating for the demand for the consumer market with certain goods associated with emerging new needs.

Although they cannot count on stable government support and do not have high returns, they are more flexible and more easily adapted to all the processes taking place in constantly changing market relationships. They can significantly change their program by introducing elements of an innovative nature. However, the lack of state support and high risks do not contribute to the growth of profitability of such companies. In general, this can lead to a process of tax avoidance.

Given the contradictory consequences of market transformation, there should be a constant search for elements of harmonizing state economic policy and freedom of enterprise in the context of developing economic relations of Russian production. Of course, the role of state participation is high. By remaining as an indicator of economic development, it seeks to mitigate the negative effects of market development. This includes antitrust policy, environmental legislation, the fight against shadow incomes, etc. The potential for high returns creates negative incentives for other sectors of the economy, which leads to a decrease in the motivation of many companies and ultimately acts as negative incentives for production activity, orienting the economy to maintain the commodity model.

Large businesses can count on substantial state support, however, large enterprises always strive for independence and independence from state control. There are problems of a productive nature in this sector, they are associated with the use of labor resources and prospects for increasing labor productivity, saving all types of resources. Productivity growth is certainly a means of increasing economic competitiveness.

Speaking about the small commodity business sector, other problems accompanying their activities are insufficient financing, market and innovative risks, a motivation system with subsequent productivity growth, increased profitability, etc. Weak demand and lack of state support significantly undermine stability and profitability in this sector [10].

\section{Discussion}

The Russian economy has always been close to a conservative scenario of economic development, which involves a small effort to develop a competitive economy. In this scenario, however, national economic dynamics will be accompanied by macroeconomic stabilization policies.

In addition, this form of market relations requires constant monitoring of budget expenditures, including limiting transfers to regional budgets. In addition, the increase in the tax burden on private entrepreneurship for a long time remains one of the problems of this sector.

Another development scenario is reformative.

On the contrary, it is aimed at reducing the tax burden on business and increasing the risks of doing business. At the same time, this means that the state is quite active in maintaining the stability of the macroeconomic environment. Changing the structure of budget expenditures in favor of investments in infrastructure and human capital, stabilizing transfers to regional budgets will lead to increased financial independence of the regions [11]. 
The growth of competitive activity of all types of business will contribute to the further development of economic relations and restructuring of the economy.

The main directions of economic development should be the redistribution of state support between all sectors, focusing not only on the success of the enterprise, but also on its strategic prospects, as well as the possibility of participating in the formation of a new type of economy [12].

It should be noticed that the reformative scenario involves attracting substantial financial resources for investment in market non-resource sectors.

Today the main priority of socio-economic development is the transition to a digital economy and the formation of an information base for digitalization of all aspects of the country's life.

The basis of the digital economy as a new reality is technological change, the results of the gradual development of all aspects of life, evolutionary and revolutionary phenomena in the progressive development of the economic system. New forms of economic relations based on information and communication technologies that yesterday acted as distant guidelines, are now firmly embedded in economic realities and become the basis for further integration of the national economy into a single system.

Digital economy is an economy based on communicative connections using technological innovations of continuous innovative and technological progress, technologies, formation of digital complexes and systems.

In this case, a new understanding of technological and social systems arises. Both the business environment itself and the participants in these relations are changing, building their communication links on new platforms.

Digitalization as an objective reality affects various components of the business environment. This includes the influence on all aspects of industrial relations: on the methodology for developing a business strategy, on the globalization of economic relations within the framework of national and world economies, etc.

The main result of the formation of such a relationship is changes in competition. First of all, the conditions of competition are changing. Any enterprise using digital technologies can overtake large competitors operating in the market for a long time. New elements of digitalization of the economy (digital platforms) allow to take full advantage of opportunities of fair competition and to form highly efficient production [13].

Another source of competitive momentum that digital technologies are shaping is the ability to integrate and blur industry boundaries. At the cross-industry level, this leads to the ability to use a single client base and a single infrastructure.

Of course, there are a number of positive effects of digitalization, this is the transparency of the subject's behavior model, quick adaptation to new development methods, the formation of new convenient marketing models, etc.

Using the information base, the business can control the consequences of any actions in different areas of the company's activity. At one time, the exchanges, acting as an information base, allowed enterprises to use a single information base and accelerate the process of turnover of financial and material resources. Digital platforms also form the basis of a single information space, forming new ways of payment, business activity indices, opportunities for digital cooperation, transforming the process of profit-making and redistribution of resources and income between sectors and sectors of the economy [14].

New business models help create efficient remote forecasting, which allows you to quickly and efficiently identify trends in the operation of equipment and equipment, the functionality of which is determined through the digital brain.

As a result, digital capital and digital technologies are becoming a new source of profit and a factor in business competitiveness. 
Employee creativity becomes an important factor in the development and competitiveness of companies working with information and communication technologies. In the context of digital transformation and the formation of the digital economy, the improvement of human capital for super-profits is not a priority. The problem of forming creative capital that can bring super-powerful income when implementing creative ideas comes to the fore. New forms of business and new forms of business cooperation in the digital economy are the reality that the largest powers of the world are today betting on the way to overcoming difficulties, meeting the needs and growing the well-being of the entire world community [15].

The basis of the entrepreneurial process has always been the creativity of employees. The use of new business models is both an impulse and the basis for the further development of this process. The constant improvement of the human factor cannot but be associated with new forms of production. On the contrary, the integration of resource potential is now taking a new stage, forming a single basis for the development of modern society.

A single digital space poses new requirements for business entities. Mobility, the ability to easily integrate into digital communications, manage all types of resources on a new platform base become an unconditional way to carry out high-yield production, while improving all aspects of its activities.

It should be bared in mind that gradually all market agents, and of course the, become participants in such relations. The consumer forces the manufacturer to always respond to the objective requirements of the market and enter the new space of relations between the seller and the buyer. By meeting the needs of all business entities, the digital network space serves as the foundation for new relationships and contributes to the full satisfaction of economic interests of both.

In the digital economy, a new organizational structure of the business is developing the block chain system (blockchain). Its advantage is the ability to move payments in a global space instantly and transparently. This saves on the cost of servicing the personnel involved in the processing of such data.

Digitalization of the economy and the formation of new organizational structures erase the boundaries between world economies, forming a single global economic space, eliminates problems arising from uncoordinated actions of organizational structures, reduces transaction costs at times and contributes to the optimization of the production process.

Digitalization as a process of improving the socio-economic space requires considerable financial investments. They should be taken into account in the socio-economic development programmes of the countries of the world community.

Table 1. Expenses for the digitalization of the Russian economy.

\begin{tabular}{|l|c|c|}
\hline Expenses & Year & Parameter,RUR \\
\hline $\begin{array}{l}\text { Gross domestic expenditure on the } \\
\text { development of the digital economy }\end{array}$ & 2018 & 3.8 trillion \\
\hline Digital Business Transformation & 2020 & 1.3 trillion \\
\hline $\begin{array}{l}\text { Scope of the national project "Digital } \\
\text { Economy of the Russian Federation" }\end{array}$ & $2019-2024$ & 1.8 trillion \\
\hline Internet Trading Market Turnover & 2020 & 1.7 trillion \\
\hline
\end{tabular}

The digitalization process is associated with significant financial costs, but it should be understood that the formation of network platforms that combine all economic entities into a single digital space is a linear process. The effect of introducing such elements will bring significant bonuses not only of a quantitative nature, but also form a single society that can 
reasonably use resources and significantly increase the profitability of any business projects.

Table 2. The most popular forms of digitalization of business processes.

\begin{tabular}{|l|c|}
\hline Forms of digitalization of business processes & Per cent, \%\% \\
\hline Data Management Technologies & 34 \\
\hline Internet of Things Technologies & 28 \\
\hline Robotization of processes and biometrics & 24 \\
\hline Artificial intelligence & 22 \\
\hline
\end{tabular}

The diversity of forms of digital transformation of society is based on the priorities of the general development of the business space and reflects the possibilities of using the resource fund of the country's economy.

Table 3. Level of digitalization of Russian business.

\begin{tabular}{|l|c|}
\hline Types of business & Digitalization level in $\% \%$ \\
\hline Medium Business & 20 \\
\hline Microbusiness and IE & $8-10$ \\
\hline Small business & $15-17$ \\
\hline Big business & 50 \\
\hline
\end{tabular}

Along with the growth of digitalization, special attention should be paid to information security, digital culture. However, about $70 \%$ of enterprises are not ready today to pay due attention to the development of digital culture, ignoring the fact that it is the basis for the further development of digital technologies. The need to pay due attention to digital culture is constantly being mentioned at all levels. The national project "Digital Economy of Russia" considers this area as one of the priority tasks (Figure 1).

\section{Development of digital infrastructure in Russian companies*}

$\%$

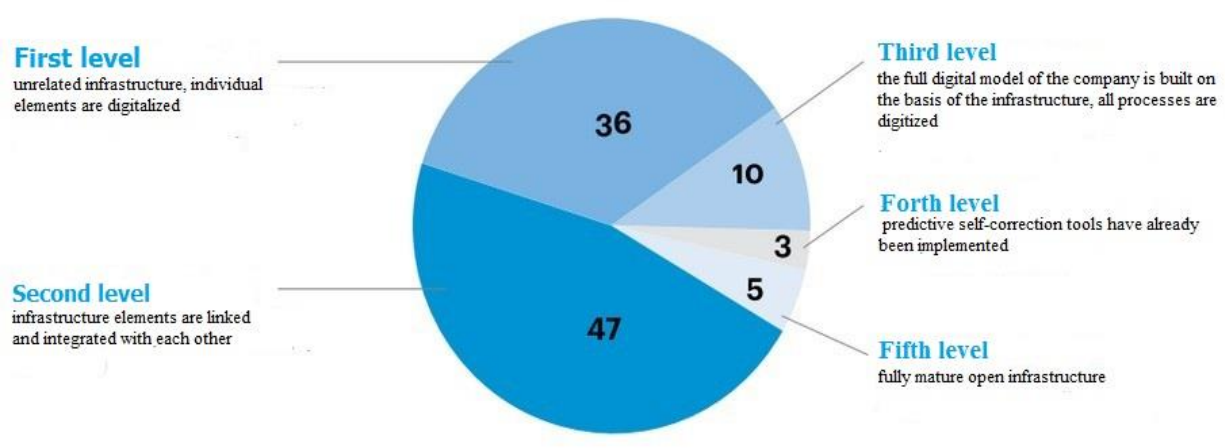

* data were rounded off

Source: KDMA survey (2020)

Fig. 1. Development of digital infrastructure in Russian companies 
Against the background of the pandemic, the digitalization process has become a prerequisite for the further progressive development of all spheres of economy. All economic entities had to respond to the new conditions for the production of public goods quickly. Russian business regularly invests in the process of digitalization of the company up to $10 \%$ of the proceeds from the sale of products, considering such investments as priority. This results in more efficient business processes.

\section{Conclusions}

The business environment is changing, these are the realities of our time, traditional forms of business are replaced by new business models that are able to form unified interethnic structures focused on the formation of high-tech production and meeting the needs of modern society.

However, at the same time, new problems arise that are associated with the possibility of the effective existence of such business models and organizational communities. The legal framework in the world today is not adapted to the new reality and does not contain legal norms that can provide an adequate legal basis for business turnover in such relations. This task of modern society today is one of the priorities.

Thus, the active implementation of network platforms in enterprises will allow integrating the development of business projects into production with maximum effect.

The advantages of digital transformation are obvious, they are simply vital in new realities. In addition to the absolute need to implement such changes, the digital transformation process itself has an undeniable economic advantage, saving all types of resources and accelerating interaction processes at all levels of social relationships. The practical implementation of digital transformation becomes an element of systemic transformations of the strategic development of society.

The main advantages of digitalization of the economy are the acceleration of economic processes in the national economy, the further development of information technologies and the digital culture of workers, as well as the country's ability to integrate into a single global digital space successfully.

\section{References}

1. G.N. Ryazanova, IFAC-PapersOnLine 52, 25, 225-230 (2019)

2. L. Becchetti, L. Bruni, S. Zamagni, The Microeconomics of Wellbeing and Sustainability. Recasting the Economic Process (Imprint Academic Press, 2020), DOI https://doi.org/10.1016/C2017-0-04428-2

3. V. Uzun, N. Shagaida, Z. Lerman, Land Use Policy 83, 475-487 (2019)

4. I. Soldatova, Political Volatility. Economics World 3, 1-2 (2015)

5. T. Zhukova, O. Panfilova, I. Avlasenko, L. Avlasenko, Peculiarities and development factors of modern agricultural engineering. XIII International Scientific and Practical Conference "State and Prospects for the Development of Agribusiness INTERAGROMASH 2020” (2020), https://doi.org/10.1051/e3sconf/202017505028

6. I.M. Peshkhoev, I.V. Avlasenko, O.V. Panfilova, Y.V. Podkolzin, O.G. Savelyeva, Advances in Intelligent Systems and Computing, 726 (2017)

7. L. Avlasenko, I. Peshkhoev, Y. Podkolzin, O. Savelyeva, E3S Web of Conferences 175, 6, 12006 (2020)

8. T.V. Zhukova, O.V. Panfilova, I.V. Avlasenko, L.M. Avlasenko, A.V. Belousova, Deformations of the Global Financial System in the Conditions of Globalization. 
International Conference Project "The future of the Global Financial System: Downfall of Harmony" ISC (2018): The Future of the Global Financial System: Downfall or Harmony pp. 774-782 (2018)

9. M. Svanidze, L. Götz, Global Food Security 21, 60-68 (2019)

10. V. Glinskiy, L. Serga, M. Alekseev, N. Amotoy, E. Simonova, Procedia Manufacturing 21, 838-845 (2018)

11. V.A. Canto, A. Wiese, Economic Disturbances and Equilibrium in an Integrated Global Economy Investment Insights and Policy Analysis (Imprint Academic Press, 2018), DOI https://doi.org/10.1016/C2017-0-00904-7

12. K.L. Higgins, Economic Growth and Sustainability. Systems Thinking for a Complex World (2015), DOI https://doi.org/10.1016/C2014-0-02358-1

13. A.M. Balisacan, U. Chakravorty, M.-L.V. Ravago, Sustainable Economic Development. Resources, Environment and Institutions (Imprint Academic Press, 2015), DOI https://doi.org/10.1016/C2013-0-15316-0

14. A.K. Tugengold, V.P. Dimitrov, L.V. Borisova, M.V. Grankov, R.N. Voloshin, Russian Engineering Research, 39(6), 510-515 (2019)

15. V. Dimitrov, L. Borisova, I. Nurutdinova, E3S Web of Conferences, 175, 05027 (2020) 